\title{
Métodos de alimentação e evolução do peso de recém- nascidos com microcefalia congênita por Zika Vírus
}

\section{Feeding methods and weight evolution in newborns with congenital microcephaly due for Zika Virus}

\author{
Andréa Monteiro Correia Medeiros ${ }^{1,2}$ (1) , Anne Jardim-Botelho 2,3 (D), \\ Emanuele Mariano de Souza Santos ${ }^{2,4}$ (D), Aline de Siqueira Alves Lopes ${ }^{2}$ (D), Felipe Batista Santos ${ }^{5}$ (D), \\ Thalyta Prata Leite de Sá ${ }^{(1)}$, Íkaro Daniel Carvalho Barreto ${ }^{6}$ (D), Cliomar Alves dos Santos ${ }^{7}$ (D), \\ Luis Eduardo Cuevas ${ }^{8}$ (D), Ricardo Queiroz Gurgel2,5
}

\begin{abstract}
RESUMO
Objetivo: investigar a forma de oferta de dieta, conforme os diversos métodos de alimentação, e descrever o ganho de peso em recém-nascidos com microcefalia relacionada ao Zika Vírus, comparando-os com recém-nascidos sem microcefalia. Método: estudo de coorte retrospectivo com caso controle aninhado. Informações sobre idade gestacional, peso e métodos de alimentação (seio materno, sonda nasogástrica/orogástrica, mamadeira e copo) foram coletadas em prontuários de 43 recém-nascidos com microcefalia por Zika Vírus, equiparados conforme idade gestacional com 43 recém-nascidos sem acometimentos (grupo controle), em uma maternidade de referência no Nordeste do Brasil. Os dados foram coletados desde o nascimento até a alta hospitalar. As medidas de desfecho foram pesos (ao nascer e na alta), velocidade de ganho de peso, tempo de internação e métodos de alimentação. Resultados: $\mathrm{O}$ grupo com microcefalia apresentou menores pesos ao nascer $(\mathrm{D}=-1,67 ; \mathrm{p}<0,001)$, inclusive com maior probabilidade de serem baixo peso ( $\mathrm{Phi}=0,687 ; \mathrm{p}<0,001$ ), e no momento da alta $(\mathrm{D}=-0,87 ; \mathrm{p}=0,006)$, do que o controle. $\mathrm{O}$ grupo com microcefalia também apresentou maior velocidade de ganho de peso $(\mathrm{D}=0,77 ; \mathrm{p}=0,006)$, embora com métodos alimentares semelhantes ao grupo controle, incluindo a aceitação do seio materno, de forma exclusiva $(34,9 \%)$ ou complementada $(58,1 \%)$. Conclusão: recém-nascidos com microcefalia relacionada ao Zika Vírus utilizaram métodos alimentares semelhantes, incluindo seio materno, aos do grupo sem acometimento. Quanto ao peso, apresentaram valores menores ao nascimento e na alta, apesar de terem um crescimento precoce pós-natal mais rápido que aqueles sem microcefalia.
\end{abstract}

Palavras-chave: Zika Vírus; Microcefalia; Recém-nascido; Ganho de peso; Métodos de alimentação

\begin{abstract}
Purpose: Investigate the form of diet offer, according to the different feeding methods, and describe the weight gain in newborns with microcephaly related to Zika Virus, comparing them with newborns without microcephaly. Methods: Retrospective cohort with nested case-control study. Information on gestational age, weight and feeding methods (maternal breast, nasogastric/ orogastric tube, bottle and cup) were collected from medical records of 43 newborns with microcephaly due to Zika Virus, matched according to gestational age with 43 newborns without involvement (control group), in a reference maternity hospital in northeastern Brazil. Data were collected from birth to hospital discharge. Outcome measures were weights (at birth and at discharge), weight gain speed, length of hospital stay and feeding methods. Results: The microcephaly group had lower weights at birth $(\mathrm{D}=-1.67$; $\mathrm{p}<0.001$ ), even more likely to be underweight $(\mathrm{Phi}=0.687 ; \mathrm{p}<0.001)$, and at discharge $(\mathrm{D}=-0.87 ; \mathrm{p}=0.006)$, than the control group. The microcephaly group also showed a higher rate of weight gain ( $D=0.77$; $\mathrm{p}=0.006$ ), although with eating methods similar to the control group, including acceptance of the mother's breast, exclusively (34.9\%) or complemented $(58.1 \%)$. Conclusion: Newborns with Zika Virus-related microcephaly used similar feeding methods, including maternal breast, to those in the non-affected group. As for weight, they showed lower values at birth and at discharge, despite having a faster postnatal early growth than those without microcephaly.
\end{abstract}

Keywords: Zika Virus; Microcephaly; Newborn; Weight gain; Feeding methods

\footnotetext{
Trabalho realizado no Curso de Fonoaudiologia, Universidade Federal de Sergipe - UFS - São Cristóvão (SE), Brasil.

${ }^{1}$ Departamento de Fonoaudiologia, Universidade Federal de Sergipe - UFS - São Cristóvão (SE), Brasil.

${ }^{2}$ Programa de Pós-graduação em Ciências da Saúde, Universidade Federal de Sergipe - UFS - Aracaju (SE), Brasil.

${ }^{3}$ Centro de Referência em Alergia Alimentar de Sergipe, Universidade Federal de Sergipe - UFS - Aracaju (SE), Brasil.

${ }^{4}$ Núcleo de Propedêutica e Terapêutica, Universidade Estadual de Ciências da Saúde de Alagoas - UNCISAL - Maceió (AL), Brasil.

${ }^{5}$ Departamento de Medicina, Universidade Federal de Sergipe - UFS - Aracaju (SE), Brasil.

${ }^{6}$ Programa de Pós-Graduação em Biometria e Estatística Aplicada, Universidade Federal Rural de Pernambuco - UFRPE - Recife (PE), Brasil.

${ }^{7}$ Laboratório Central de Saúde Pública de Sergipe - Aracaju (SE), Brasil.

${ }^{8}$ Liverpool School of Tropical Medicine - Pembroke Place - Liverpool, United Kingdom.

Conflito de interesses: Não.

Contribuição dos autores: $A M C M$ foi responsável pela concepção e desenho do estudo, por entrar em contato com as autoridades locais de saúde e organizar o trabalho de campo, coleta e interpretação de dados, escrita e revisão crítica do manuscrito; $A J B$ foi responsável pelo desenho do estudo, análise e interpretação de dados, escrita e revisão crítica do manuscrito; $E M S S$ foi responsável pela coleta de dados e revisão crítica do manuscrito; $A S A L$ foi responsável pela coleta de dados e revisão crítica do manuscrito; $F B S$ foi responsável pela coleta de dados e revisão crítica do manuscrito; TPLS foi responsável pela coleta de dados, escrita e revisão crítica do manuscrito; ÍDCB foi responsável pela análise estatística e interpretação dos dados, escrita e revisão crítica do manuscrito; $C A S$ foi responsável pela coleta de dados; $L E C$ foi responsável pela interpretação de dados; escrita e revisão crítica do manuscrito; $R Q G$ foi responsável pela concepção e desenho do estudo, por entrar em contato com as autoridades locais de saúde e organizar o trabalho de campo, interpretação de dados e revisão crítica do manuscrito.

Financiamento: Nada a declarar.
}

Autor correspondente: Andréa Monteiro Correia Medeiros. E-mail: andreamcmedeiros@gmail.com

Recebido: Agosto 17, 2020; Aceito: Dezembro 07, 2020 


\section{INTRODUÇÃO}

No final do ano de 2014, houve um aumento no número de recém-nascidos $(\mathrm{RN})$ com microcefalia no Brasil, justamente em áreas geográficas onde o Zika Vírus (ZKV) havia surgido. Estudos epidemiológicos e de coorte estabeleceram uma forte relação do ZKV com infecções intrauterinas ${ }^{(1,2)}$. Com o surto do $\mathrm{ZKV}$, foi identificada uma síndrome congênita, inicialmente mal definida, caracterizada por microcefalia, encefalopatia, baixa estatura, baixo peso e problemas de alimentação ${ }^{(3,4)}$.

Há na literatura falta de consenso no que diz respeito às características de nascimento das crianças com microcefalia relacionada ao ZKV. Enquanto alguns autores afirmam que o baixo peso ao nascer e a prematuridade são apontados como desfechos adversos mais frequentes da infecção pelo $\mathrm{ZKV}^{(5)}$, outros acreditam que, apesar de crianças com microcefalia apresentarem maior probabilidade de ter baixo peso ao nascer, a frequência de prematuridade não é alta ${ }^{(6,7)}$.

Crianças com microcefalia relacionada ao $\mathrm{ZKV}$, mesmo quando têm peso e comprimento normais ao nascimento ${ }^{(8)}$, apresentam deterioração de seu estado nutricional, com prevalência duas vezes maior de baixo peso para a idade no segundo ano de vida, quando comparadas às crianças não infectadas ${ }^{(9)}$. Estudos clínicos sobre o fornecimento de nutrição complementar ao RN de risco são necessários, visto que o crescimento inadequado pode estar relacionado a um neurodesenvolvimento insatisfatório ${ }^{(10)}$.

O Ministério da Saúde do Brasil ${ }^{(11,12)}$ e a Organização Mundial de Saúde ${ }^{(13)}$ recomendam o aleitamento materno exclusivo até os 6 meses de vida e complementado até 2 anos de idade, incluindo as crianças nascidas de mães com suspeita, provável ou confirmada, de infecção pelo ZKV. O início e a manutenção bem-sucedida do aleitamento materno dependem de habilidades eficientes, que podem ser uma tarefa complexa demais aos sujeitos com microcefalia.

A Fonoaudiologia se preocupa com a forma de oferta de alimentação, que pode incluir a necessidade do uso de uma via de alimentação alternativa (por exemplo, alimentação por copo, mamadeira ou sonda orogástrica - SOG) para que o neonato consiga receber a dieta e atingir crescimento adequado ${ }^{(14,15)}$. Embora as dificuldades alimentares estejam bem documentadas em crianças com deficiências neurológicas, os dados ainda são escassos sobre as populações afetadas por $\mathrm{ZKV}^{(16)}$. O manejo nutricional desses RNs passou a ser um desafio para os profissionais de saúde em áreas endêmicas.

Estudos apontaram que crianças com microcefalia relacionada ao ZKV apresentam dificuldades na ingesta alimentar, que podem estar relacionadas tanto a alterações no tônus dos músculos orofaciais, que interferem no vedamento labial adequado, na sucção e nos movimentos de língua ${ }^{(17)}$, como a condições adversas associadas à textura dos alimentos, ao tempo prolongado das refeições e a distúrbios nos mecanismos de fome e saciedade ${ }^{(3,4)}$.

Faltam, ainda, estudos sobre o padrão de crescimento, incluindo o ganho de peso inicial, conforme os métodos alimentares utilizados durante a hospitalização na maternidade. O objetivo do presente estudo foi investigar a forma de oferta de dieta, conforme os diversos métodos de alimentação, e descrever o ganho de peso do nascimento até a alta hospitalar, em RNs com microcefalia relacionada ao ZKV, comparando-os com RNs sem acometimento.

\section{MÉTODOS}

Trata-se de um estudo de coorte, retrospectivo, com caso controle aninhado de 86 RNs nascidos entre fevereiro de 2015 e março de 2017 , durante o período do surto de ZKV, que ocasionou nascimentos com microcefalia na Região Nordeste do Brasil. Todos os RNs pertenciam à mesma maternidade pública, referência ao alto risco, tendo seus dados levantados a partir dos registros hospitalares.

Foram identificados 43 RNs que se adequavam ao "Protocolo de Vigilância em Resposta à Ocorrência de Microcefalia relacionada à Infecção por ZKV"(18), sendo classificados como pertencentes ao grupo de estudo com microcefalia (GM), pareados, conforme idade gestacional ao nascimento (IGN), com 43 RNs do grupo controle sem microcefalia (GC).

Como critérios de inclusão no GM, foi considerada a medida do perímetro cefálico menor que dois desvios padrão, segundo o esperado para o sexo e a idade gestacional (IG). A microcefalia foi relacionada ao ZKV após exclusão de outras etiologias (citomegalovírus, rubéola, toxoplasmose, HIV, sífilis) e pela evidência de infecção fetal por ZKV, com base em critérios clínicos e epidemiológicos, conforme o Ministério da Saúde e a literatura internacional ${ }^{(11,12)}$

Como critérios de inclusão no GC, foi considerada a medida do perímetro cefálico quando adequada, conforme o sexo e a IG. Foi observada, também, a IGN, que deveria ser correspondente aos participantes do GM.

Foram considerados como critérios de exclusão, para ambos os grupos (GM e GC), RNs que apresentassem instabilidade clínica caracterizada por dispneia, cianose e/ou taquicardia. $\mathrm{O}$ RN do GC também não poderia apresentar evidência de infecção fetal por ZKV, segundo parâmetros estabelecidos ${ }^{(11,12)}$.

Os dados coletados incluíram IG, peso ao nascer, diagnóstico de microcefalia conforme exames realizados (tomografia computadorizada, ultrassonografia e sorologia para ZKV), medidas de peso e métodos de alimentação (seio materno - SM, sonda nasogástrica/orogástrica, mamadeiras com bico comum ou ortodôntico e copo), durante todo o período de internação hospitalar.

Os métodos de alimentação utilizados por cada RN foram extraídos da prescrição médica e evolução clínica da equipe, visto que nem todos os participantes realizaram acompanhamento fonoaudiológico, para que pudessem ser obtidos dados específicos sobre o desenvolvimento motor oral. Por outro lado, os métodos utilizados, de certa forma, já poderiam evidenciar a habilidade oral do RN.

Além disso, por se tratar de uma instituição que preconiza a assistência neonatal humanizada, conforme a Iniciativa Hospital Amigo da Criança (IHAC) ${ }^{(19)}$, havia o esforço de toda equipe de saúde, incluindo o fonoaudiólogo, em priorizar, quando possível, a indicação do aleitamento materno, que pressupõe habilidade motora oral.

Os dados foram analisados usando o software R Core Team 2018, versão 3.5.1. As variáveis foram resumidas utilizando frequências, porcentagens, intervalos de confiança de $95 \%$ (IC 95\%) e médias com desvio padrão (DP). As associações entre variáveis categóricas foram testadas pelo teste Exato de Fisher, Qui-quadrado de Pearson e riscos relativos com IC 95\%. Foi calculado o tamanho de efeito Coeficiente Phi para proporções. As variáveis normalmente distribuídas foram 
testadas usando o teste $t$ de Student e as que não eram, com o teste de Mann-Whitney.

Foi utilizado o Tamanho de Efeito D de Cohen para quantificar as diferenças de medida de tendência central ${ }^{(20)}$. As regressões lineares foram utilizadas para estimar as diferenças de velocidade de ganho de peso (gramas/dia) entre RNs com e sem microcefalia, ajustadas pelo número de dias, até a alta, e métodos de alimentação. Os valores de $\mathrm{p}$ foram ajustados pelo método de Benjamini-Hochber ${ }^{(21)}$. Os valores de $\mathrm{p}<0,05$ foram considerados estatisticamente significativos.

O estudo foi aprovado pelo Comitê de Ética em Pesquisa da Universidade Federal de Sergipe, ${ }^{\circ}$ CAEE 53611316.0.0000.5546. Todos os responsáveis assinaram o Termo de Consentimento Livre e Esclarecido (TCLE) para inclusão na pesquisa.

\section{RESULTADOS}

Todos os RNs incluídos no estudo estiveram hospitalizados por, pelo menos, 4 dias. Os RNs com microcefalia (GM) estiveram internados na maternidade para seguir o protocolo de investigação do ZKV e aqueles sem microcefalia (GC), por motivos diversos, incluindo diabetes gestacional, para investigar possíveis infecções após ruptura prematura de membranas e infecções urinárias maternas.

A Tabela 1 apresenta as características clínicas dos neonatos, incluindo IG e peso ao nascimento, além das intercorrências clínicas. Não houve diferenças entre os grupos GM e GC para IGN e intercorrências clínicas (uso de suporte respiratório e antibioticoterapia), o que garantiu uniformidade dos participantes quanto a esses parâmetros clínicos (Tabela 1).
Quanto ao peso, a Tabela 1 mostra o peso ao nascimento, ganho ponderal e velocidade de ganho durante a internação. Observou-se diferença no ganho de peso corporal entre os grupos, desde o nascimento até a alta hospitalar. O GM apresentou menores pesos ao nascer, após 48 horas de vida e na alta hospitalar. Porém, teve maior ganho ponderal global e maior taxa diária de ganho de peso. Apesar disso, todos os RNs do estudo (com e sem microcefalia) apresentaram tempo de hospitalização semelhante (Tabela 1).

A Tabela 2 apresenta os métodos de alimentação utilizados durante a internação, incluindo SM exclusivo, ou não (complemento por meio de copo, mamadeira ou SOG), e ausência do SM, comparando RNs com e sem microcefalia. Não houve diferenças entre os grupos quanto à oferta de SM, uso de sonda nasogástrica/orogástrica, mamadeiras ou copo. Houve apenas uma tendência maior ao uso de SOG no GM, contudo não significativa (Tabela 2).

Na Figura 1, é apresentada a prevalência do início da amamentação, conforme os dias (do nascimento ao $37^{\circ}$ dia de vida). Observou-se que $58 \%$ dos RNs do GM e 70\% dos RNs do GC foram levados ao SM logo ao nascimento. Entretanto, $14 \%$ do GM começou a mamar somente após 5 dias de vida, especificamente com 5, 6, 7, 8, 13 e 37 dias após o nascimento, enquanto nenhum RN do GC iniciou o SM tão tardiamente (Figura 1).

A Tabela 3 apresenta os parâmetros de regressão ajustados para velocidade de ganho de peso, comparando RNs com e sem microcefalia. Quanto aos métodos de alimentação e tempo de internação (dias até a alta), houve diferença entre velocidade de ganho de peso neonatal e presença da microcefalia, com velocidade média de ganho de peso de $81,3 \mathrm{~g} / \mathrm{dia}$, sendo maior nos RNs do $\mathrm{GM}$, quando comparados aos do $\mathrm{GC}(\mathrm{p}=0,002)$, após ajuste dos valores de $\mathrm{p}$ pelo método de Benjamini-Hochber ${ }^{(21)}$ (Tabela 3 ).

Tabela 1. Características clínicas e ganho de peso de recém-nascidos com e sem microcefalia

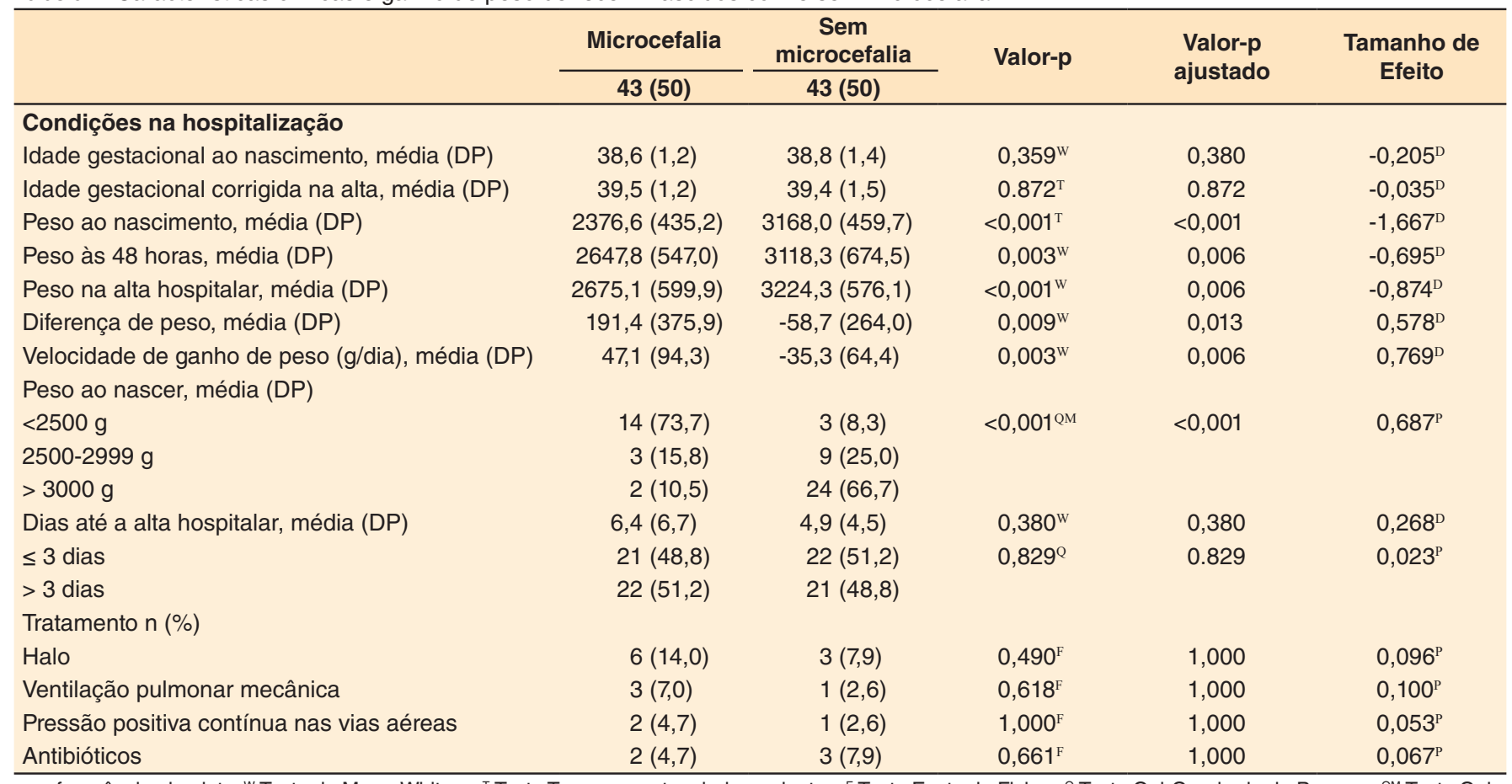

$\mathrm{n}$ - frequência absoluta. ${ }^{\mathrm{W}}$ Teste de Mann-Whitney; ${ }^{\top}$ Teste T para amostras independentes; ${ }^{\mathrm{F}}$ Teste Exato de Fisher; ${ }^{\circ}$ Teste Qui-Quadrado de Pearson; ${ }^{\text {QM }}$ Teste QuiQuadrado de Pearson estimado via procedimento Monte-Carlo; ${ }^{D} \mathrm{D}$ de Cohen; ${ }^{\mathrm{P}}$ Coeficiente Phi; Os valores de $\mathrm{p}$ foram ajustados para a taxa de descoberta falsa pelo método Benjamini-Hochberg

Legenda: DP = desvio padrão; $\mathrm{g}=$ gramas; $\mathrm{g} / \mathrm{dia}=$ gramas por dia; $\mathrm{n}=$ frequência absoluta; \% = percentual 
Tabela 2. Métodos de alimentação utilizados durante a internação hospitalar dos recém-nascidos com e sem microcefalia

\begin{tabular}{|c|c|c|c|c|c|c|}
\hline \multirow{3}{*}{ Métodos de alimentação n (\%) } & \multicolumn{2}{|c|}{ Grupo } & \multirow{3}{*}{ Valor-p } & \multirow{3}{*}{$\begin{array}{l}\text { Valor-p } \\
\text { ajustado }\end{array}$} & \multirow{3}{*}{$\begin{array}{c}\text { Tamanho de } \\
\text { Efeito }\end{array}$} & \multirow{3}{*}{ RR (IC 95\%) } \\
\hline & Microcefalia & $\begin{array}{c}\text { Sem } \\
\text { microcefalia }\end{array}$ & & & & \\
\hline & $43(53)$ & $38(47)$ & & & & \\
\hline SM exclusivo & $15(34,9)$ & $18(47,4)$ & 0,268 & 1,000 & 0,130 & $0,74(0,43-1,25)$ \\
\hline SM + copo ou mamadeira ou SOG & $25(58,1)$ & $18(47,4)$ & 0,377 & 1,000 & 0,110 & $1,23(0,81-1,87)$ \\
\hline Copo & $20(46,5)$ & $18(47,4)$ & 1,000 & 1,000 & 0,009 & $0,98(0,62-1,56)$ \\
\hline Mamadeira & $4(9,3)$ & $2(5,3)$ & 0,679 & 1,000 & 0,077 & $1,76(0,34-9,11)$ \\
\hline SOG & $10(23,3)$ & $3(7,9)$ & 0,074 & 1,000 & 0,209 & $2,95(0,87-9,92)$ \\
\hline Sem SM & $3(7,0)$ & $2(5,3)$ & 1,000 & 1,000 & 0,032 & $1,32(0,23-7,52)$ \\
\hline
\end{tabular}

$\mathrm{n}$ - frequência absoluta. Teste exato de Fisher; RR - Risco Relativo. Coeficiente Phi. Os valores de $\mathrm{p}$ foram ajustados para a taxa de descoberta falsa pelo método Benjamini-Hochberg

Legenda: $\mathrm{SM}=$ seio materno, $\mathrm{SOG}$ = sonda orogástrica; $\mathrm{IC}$ = Intervalo de confiança

Tabela 3. Modelo de regressão ajustado para velocidade de ganho de peso em recém-nascidos com microcefalia em comparação com aqueles sem microcefalia

\begin{tabular}{|c|c|c|c|c|}
\hline & B (IC 95\%) & Valor-p & $\mathrm{B}_{\mathrm{adj}}(\mathrm{IC} 95 \%)$ & Valor-p \\
\hline \multicolumn{5}{|l|}{ Grupo } \\
\hline GM & $82,4(35,9 ; 129,0)$ & 0,001 & $81,3(31,9 ; 130,7)$ & 0,002 \\
\hline GC & 1 & & 1 & \\
\hline \multicolumn{5}{|l|}{ Métodos de alimentação } \\
\hline SM exclusivo & $-124,1(-255,0 ; 6,72)$ & 0,062 & $-114,6(-233,3 ; 4,1)$ & 0,058 \\
\hline $\mathrm{SM}+$ copo ou mamadeira ou SOG & $-68,0(-195,0 ; 59,0)$ & 0,286 & $-62,6(-177,9 ; 52,7)$ & 0,278 \\
\hline Sem SM & 1 & & 1 & \\
\hline \multicolumn{5}{|l|}{ Dias até a alta } \\
\hline$>3$ dias & $-28,0(-79,2 ; 23,2)$ & 0,276 & $9,7(-44,5 ; 63,9)$ & 0,719 \\
\hline$\leq 3$ dias & 1 & & 1 & \\
\hline
\end{tabular}

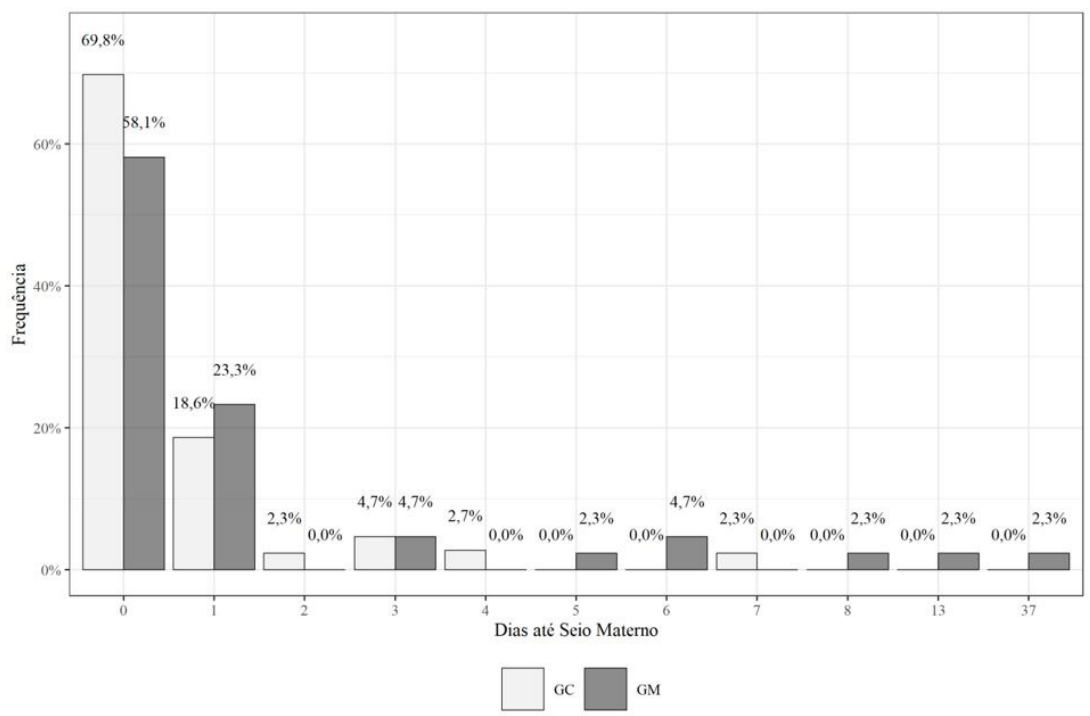

Figura 1. Prevalência do início da amamentação, em dias (0 ao 37 após o nascimento)

Legenda: $\mathrm{GM}=$ grupo com microcefalia por Zika Vírus; $\mathrm{GC}=$ grupo controle

\section{DISCUSSÃO}

Na população com microcefalia aqui estudada, houve aceitação estatisticamente semelhante, embora não significativa, quanto aos métodos de alimentação utilizados em RNs sem acometimento, apesar de ter sido observado maior uso de SOG em RNs do GM. A literatura também referiu instalação de
SOG em situações especificas, como engasgos persistentes ${ }^{(17)}$. Vários fatores são relatados na alimentação, a depender do grau de comprometimento neurológico, incluindo condições relacionadas à textura dos alimentos, ao tempo prolongado das refeições, com estresse e fadiga, aos distúrbios nos mecanismos de fome e saciedade, entre outros ${ }^{(3,4)}$.

A semelhança na aceitação do SM em ambos os grupos, apesar da iniciação mais tardia e em menor proporção em alguns 
participantes com microcefalia, poderia ser atribuída ao fato de a instituição referência do estudo seguir as orientações da Política Nacional de Enfrentamento à Microcefalia ${ }^{(11,18)}$, que, em consonância com demais entidades, instituiu práticas de incentivo ao aleitamento materno, mesmo na presença do cenário de ZKV. Também não houve diferenças entre os grupos para os demais métodos de alimentação: copo, mamadeira e SOG.

Quanto à oferta da dieta por via oral para complementar o SM, vale dizer que instituições que seguem as diretrizes da $\mathrm{IHAC}^{(19)}$ evitam a prescrição de bicos artificiais, o que provavelmente pode explicar o maior uso do copo do que da mamadeira para os RNs de ambos os grupos. Apesar dessa prática, estudo longitudinal evidenciou alta incidência do uso de mamadeira $(89,9 \%)$ em idades mais avançadas na população acometida pelo $Z K V^{(17)}$. Preconiza-se que haja a intervenção fonoaudiológica para acompanhamento dos diversos métodos de alimentação $^{(15)}$.

As normativas do Ministério da Saúde ${ }^{(11,12)}$, que recomendam o aleitamento materno em RNs suspeitos de infecção congênita pelo ZKV, foram seguidas na população com microcefalia do presente estudo, sendo consideradas, nesse contexto, uma importante estratégia de promoção da saúde e prevenção de doenças, tanto da infância como da vida adulta. Além disso, os dados aqui obtidos evidenciaram resultados satisfatórios quanto ao ganho de peso nesse período inicial de vida.

O pareamento entre os grupos GM e GC, quanto à IGN e ao perfil de intercorrências clínicas garantiu a uniformidade para fins de comparação. Todos os RNs do estudo apresentaram IGN superior a 37 semanas, não sendo considerados prematuros ${ }^{(22)}$. Esses resultados reafirmam o relato da Sociedade Brasileira de Genética Médica, que, após revisar 35 casos de microcefalia por provável infecção do ZKV, verificou que a maioria dos bebês da sua amostra nasceu a termo ${ }^{(23)}$. O nascimento a termo favorece a maturidade das funções orofaciais e capacidade de coordenação de sucção/deglutição/respiração ${ }^{(9)}$, para aceitação de via oral plena e segura.

Apesar da IGN favorável, no presente estudo, os RNs do GM tiveram quase nove vezes mais chances de ter baixo peso ao nascer (74\%) do que os do GC. Esse índice é superior à prevalência de $30 \%$ relatada pela literatura ${ }^{(24)}$, que reflete a restrição de crescimento intrauterino ao $\mathrm{ZKV}^{(6,7)}$ e outras infecções congênitas, como dengue ${ }^{(25)}$ e TORCH (toxoplasmose, rubéola, citomegalovírus e herpes simples) ${ }^{(26)}$. Assim, RNs do GM, embora fossem mais leves ao nascer e na alta, apresentaram maior velocidade de ganho de peso do que os RNs do GC, sugerindo a presença de recuperação ponderal.

Estudo referiu que a rápida velocidade de ganho de peso pós-natal em RNs com baixo peso ao nascer pode resultar em melhores resultados neurológicos ${ }^{(27)}$. Talvez o estímulo de recuperação ponderal possa aliviar a possível desnutrição futura, justamente em uma população que costuma apresentar dificuldades alimentares, relacionadas às habilidades de mastigação e deglutição, associadas a anomalias progressivas do desenvolvimento, motor e neurológicas ${ }^{(9,28,29)}$. Porém, mais estudos ainda precisam ser realizados nesse sentido.

Vale dizer que o rápido ganho de peso ocorreu independentemente dos métodos alimentares utilizados, já que não houve diferenças entre os grupos sobre o modo de oferta da alimentação. Destacase a realidade institucional, que segue os preceitos da IHAC ${ }^{(19)}$, que preconiza e incentiva o aleitamento materno, além de ter o fonoaudiólogo na equipe interdisciplinar, o que poderia justificar a conduta de intervenção precoce adequada.
Por outro lado, a rápida velocidade de ganho de peso do GM sugere a presença de alterações adaptativas nos padrões metabólicos (hipótese do fenótipo econômico), que podem aumentar o risco de sobrepeso e comorbidades futuras ${ }^{(10)}$ e merece ser melhor investigada em estudos longitudinais junto a essa população.

Sobretudo, frente aos achados do presente estudo, sobre a rápida velocidade de ganho de peso na população afetada, o aleitamento materno e boas práticas alimentares poderiam contribuir com importante repercussão positiva para o crescimento e boa nutrição pós-natal, em que dificuldades crescentes para alimentar essas crianças são relatadas ${ }^{(17,30)}$. Dessa forma, deve-se promover a sucção ao seio independentemente da patologia do $\mathrm{RN}$, desde que haja condições clínicas e que seja dado todo suporte multidisciplinar, principalmente fonoaudiológico, ao binômio mãe-bebê.

Evidenciar a aceitação dos diversos métodos de alimentação por via oral em RNs com microcefalia, com destaque para o SM, pode ser considerado um diferencial importante desta pesquisa, contribuindo para a reflexão sobre condutas precoces junto à população acometida. Houve limitação em relação aos poucos casos acompanhados, devido ao diagnóstico da microcefalia com suspeita da etiologia pelo ZKV - conforme critérios estabelecidos na literatura nacional e internacional ${ }^{(11,12)}-$ ter sido levantado somente na ocasião de nascimento da população afetada, dado o caráter inédito da epidemia.

Outro fator limitador do presente estudo é que só houve o acompanhamento dos participantes até a alta hospitalar, não sendo possível elucidar sobre o desenvolvimento alimentar posterior. Vale lembrar que a literatura tem descrito que, em idades mais avançadas, crianças com microcefalia apresentam desmame antes dos 6 meses de vida ${ }^{(17)}$, problemas alimentares, como disfagia a partir do terceiro mês de vida e deterioração do estado nutricional no segundo ano de vida ${ }^{(9)}$. Novos estudos deverão ser propostos nesse sentido.

\section{CONCLUSÃO}

RNs com microcefalia apresentaram alta prevalência de baixo peso ao nascer e experimentaram rápido crescimento pós-natal, apesar de terem métodos de alimentação semelhantes àqueles estabelecidos aos RNs do grupo controle.

$\mathrm{O}$ desconhecimento dos efeitos do ZKV em médio e longo prazo dificulta o prognóstico e o manejo clínico e nutricional e clama por novos estudos sobre o desfecho da alimentação na primeira infância, inclusive, envolvendo aspectos fonoaudiológicos, sobretudo nas questões de motricidade orofacial da população com microcefalia por ZKV.

\section{REFERÊNCIAS}

1. Nunes ML, Carlini CR, Marinowic D, Neto FK, Fiori HH, Scotta $\mathrm{MC}$, et al. Microcephaly and Zika virus: a clinical and epidemiological analysis of the current outbreak in Brazil. J Pediatr (Rio J). 2016 Maio;92(3):230-40. http://dx.doi.org/10.1016/j.jped.2016.02.009. PMid:27049675.

2. França GVA, Pedi VD, Garcia MHO, Carmo GMI, Leal MB, Garcia LP Síndrome congênita associada à infecção pelo vírus Zika em nascidos vivos no Brasil: descrição da distribuição dos casos notificados e confirmados em 2015-2016. Epidemiol Serv Saude. 2018 Jun;27(2):e2017473. http:// dx.doi.org/10.5123/S1679-49742018000200014. PMid:29972474. 
3. Cauchemez S, Besnard M, Bompard P, Dub T, Guillemette-Artur $\mathrm{P}$, Eyrolle-Guignot D, et al. Association between Zika virus and microcephaly in French Polynesia, 2013-15: a retrospective study. Lancet. 2016 Maio;387(10033):2125-32. http://dx.doi.org/10.1016/ S0140-6736(16)00651-6. PMid:26993883.

4. Prata-Barbosa A, Martins MM, Guastavino AB, Cunha AJLA. Effects of Zika infection on growth. J Pediatr (Rio J). 2019 Mar;95(Suppl 1):30-41. http://dx.doi.org/10.1016/j.jped.2018.10.016. PMid:30593788.

5. Rodrigues MSP, Costa MCN, Barreto FR, Brustulin R, Paixão ES, Teixeira MG. Repercussões da emergência do vírus Zika na saúde da população do estado do Tocantins, 2015 e 2016: estudo descritivo. Epidemiol Serv Saude. 2020 Jul;29(4):e2020096. http://dx.doi. org/10.5123/S16/79-49742020000400008. PMid:32756832.

6. França GVA, Schuler-Faccini L, Oliveira WK, Henriques CMP, Carmo EH, Pedi VD, et al. Congenital Zika virus syndrome in Brazil: a case series of the first 1501 livebirths with complete investigation. Lancet. 2016 Ago;388(10047):891-7. http://dx.doi.org/10.1016/ S0140-6736(16)30902-3. PMid:27372398.

7. de Araújo TVB, Rodrigues LC, de Alencar Ximenes RA, de Barros Miranda-Filho D, Montarroyos UR, de Melo APL, et al. Association between Zika virus infection and microcephaly in Brazil, January to May, 2016: preliminary report of a case-control study. Lancet Infect Dis. 2016 Dez;16(12):1356-63. http://dx.doi.org/10.1016/S14733099(16)30318-8. PMid:27641777.

8. França TL, Medeiros W, Souza N, Longo E, Pereira S, França T, et al. Growth and development of children with microcephaly associated with congenital Zika Virus Syndrome in Brazil. Int J Environ Res Public Health. 2018 Set 13;15(9):1990. http://dx.doi.org/10.3390/ ijerph15091990. PMid:30216976.

9. Dos Santos SFM, Soares FVM, de Abranches AD, da Costa ACC, Moreira MEL, de Matos Fonseca V. Infants with microcephaly due to ZIKA virus exposure: nutritional status and food practices. Nutr J. 2019 Dez 11;18(1):4. http://dx.doi.org/10.1186/s12937-019-0429-3. PMid:30634976.

10. Harding JE, Cormack BE, Alexander T, Alsweiler JM, Bloomfield FH. Advances in nutrition of the newborn infant. Lancet. 2017 Abr;389(10079):1660-8. http://dx.doi.org/10.1016/S0140-6736(17)305524. PMid:28443560.

11. Brasil. Orientações integradas de vigilância e atenção à saúde no âmbito da Emergência de Saúde Pública de Importância Nacional [Internet]. Brasília: Ministério da Saúde; 2017 [cited 2020 Nov 3]. 99 p. Available from: http://bvsms.saude.gov.br/bvs/publicacoes/ orientacoes_integradas_vigilancia_atencao_emergencia_saude_publica. pdf

12. Moore CA, Staples JE, Dobyns WB, Pessoa A, Ventura CV, Fonseca $\mathrm{EB}$, et al. characterizing the pattern of anomalies in congenital Zika syndrome for pediatric clinicians. JAMA Pediatr. 2017 Mar 1;171(3):28895. http://dx.doi.org/10.1001/jamapediatrics.2016.3982. PMid:27812690.

13. WHO: World Health Organization. Infant feeding in areas of Zika virus transmission [Internet]. Geneva: WHO; 2019 [cited 2020 Nov 3]. Available from: https://www.who.int/elena/titles/zika_breastfeeding/en/

14. Lubbe W. Clinicians guide for cue-based transition to oral feeding in preterm infants: an easy-to-use clinical guide. J Eval Clin Pract. 2018 Fev 2;24(1):80-8. http://dx.doi.org/10.1111/jep.12721. PMid:28251754.

15. Medeiros AMC, Bernardi AT. Alimentação do recém-nascido pré-termo: aleitamento materno, copo e mamadeira. Rev Soc Bras Fonoaudiol. 2011 Mar;16(1):73-9. http://dx.doi.org/10.1590/S1516-80342011000100014.

16. Rybak A. Organic and nonorganic feeding disorders. Ann Nutr Metab. 2015;66(Suppl 5):16-22. PMid:26226993.
17. Fábia Cabral Cavalcanti A, Aguiar YPC, Oliveira Melo ASD, Leite Cavalcanti A, D’Ávila S. Breastfeeding Behavior in Brazilian Children with Congenital Zika Syndrome. Int J Dent. 2020 Mar 16;2020:1-6. http://dx.doi.org/10.1155/2020/1078250. PMid:32256591.

18. Brasil. Ministério da Saúde. Secretaria de Vigilância da Saúde. Protocolo de vigilância e resposta à microcefalia relacionada à infecção pelo Vírus Zika. Versão 12. Brasília: Ministério da Saúde; 2015.

19. Brasil. Ministério da Saúde. Iniciativa Hospital Amigo da Criança: revista, atualizada e ampliada para o cuidado integrado Módulo 4 Autoavaliação e monitoramento do hospital. Brasília: Ministério da Saúde; 2010.

20. Sawilowsky SS. New effect size rules of thumb. J Mod Appl Stat Methods. 2009 Nov 1;8(2):597-9. http://dx.doi.org/10.22237/ jmasm/1257035100.

21. Chen X, Doerge RW, Heyse JF. Multiple testing with discrete data: proportion of true null hypotheses and two adaptive FDR procedures. Biom J. 2018 Jul;60(4):761-79. http://dx.doi.org/10.1002/bimj.201700157. PMid:29748972.

22. WHO: World Health Organization. Preterm birth [Internet]. Geneva: WHO; 2018 [cited 2020 Jun 17]. Available from: https://www.who. int/en/news-room/fact-sheets/detail/preterm-birth

23. Schuler-Faccini L, Ribeiro EM, Feitosa IML, Horovitz DDG, Cavalcanti DP, Pessoa A, et al. Possible association between Zika Virus infection and microcephaly: Brazil, 2015. MMWR Morb Mortal Wkly Rep. 2016 Jan 29;65(3):59-62. http://dx.doi.org/10.15585/mmwr.mm6503e2. PMid:26820244.

24. Carvalho-Sauer R, Costa MCN, Barreto FR, Teixeira MG. Congenital Zika Syndrome: prevalence of low birth weight and associated factors. Bahia, 2015-2017. Int J Infect Dis. 2019 Maio;82:44-50. http://dx.doi. org/10.1016/j.ijid.2019.02.040. PMid:30831221.

25. Brasil. Ministério da Saúde. Secretaria de Vigilância em Saúde. Diretoria Técnica de Gestão. Dengue: diagnóstico e manejo clínico adulto e criança. Brasília: Ministério da Saúde; 2013. 80 p. Série A. Normas e Manuais Técnicos.

26. Chung MH, Shin CO, Lee J. TORCH (toxoplasmosis, rubella, cytomegalovirus, and herpes simplex virus) screening of small for gestational age and intrauterine growth restricted neonates: efficacy study in a single institute in Korea. Korean J Pediatr. 2018;61(4):11420. http://dx.doi.org/10.3345/kjp.2018.61.4.114. PMid:29713357.

27. Johnson W, Bann D, Hardy R. Infant weight gain and adolescent body mass index: comparison across two British cohorts born in 1946 and 2001. Arch Dis Child. 2018 Out;103(10):974-80. http://dx.doi. org/10.1136/archdischild-2017-314079. PMid:29674515.

28. Vianna RAO, Lovero KL, Oliveira SA, Fernandes AR, Santos TCS, Lima LCSS, et al. Children born to mothers with rash during Zika Virus epidemic in Brazil: First 18 months of life. J Trop Pediatr. 2019 Dez;65(6):592-602. http://dx.doi.org/10.1093/tropej/fmz019. PMid:31006031.

29. Penagini F, Mameli C, Fabiano V, Brunetti D, Dilillo D, Zuccotti G. Dietary intakes and nutritional issues in neurologically impaired children. Nutrients. 2015 Nov 13;7(11):9400-15. http://dx.doi. org/10.3390/nu7115469. PMid:26580646.

30. Leal MC, van der Linden V, Bezerra TP, de Valois L, Borges ACG, Antunes MMC, et al. Characteristics of dysphagia in infants with microcephaly caused by congenital Zika Virus infection, Brazil, 2015. Emerg Infect Dis. 2017 Ago;23(8):1253-9. http://dx.doi.org/10.3201/ eid2308.170354. PMid:28604336. 